\title{
AN APPRECIATION OF BRONCHOSPIROMETRY AS A METHOD OF INVESTIGATION BASED ON 125 CASES
}

\author{
BY \\ H. A. FLEMING AND L. R. WEST \\ From Sully Hospital, Glamorgan
}

(RECEIVED FOR PUBLICATION OCTOBER 11, 1954)

Bronchospirometry has for many years been a recognized method of investigating separately the function of each lung in chest disease in Scandinavia and the United States, but it has enjoyed little favour in Great Britain and is still regarded by many with disapproval. It is variously said that the information gained is of little use in the assessment of the cases, or that the procedure is too difficult to carry out, or that the trouble and danger to the patient are too great (Prime and McMichael, 1952). Little more than fleeting reference has been made to it in the British literature and no British series has been published. Donald (1952), in a general paper, has presented the subject in a very fair light, but many personal communications convince us that his views are far from being accepted. As we are confident that none of the criticisms mentioned can be made when the Carlens catheter (Carlens, 1949) is used, we present the follow-up and general observations on 125 cases investigated by this method.

Björkman (1934) has reviewed the methods used before 1932, most of these being on animals. It was not until 1932 that Jacobaeus, Frenckner, and Björkman introduced a bronchoscopic method, and successful attempts were made in human subjects. Subsequent developments led to the introduction of the catheters of Gebauer (1939), Zavod (1940), and Norris, Long, and Oppenheimer (1948). All of these have several disadvantages, the chief of which are the effects of resistance breathing (Cain and Otis, 1949), the difficulties of manipulation, and the need for fluoroscopic control.

The introduction of the Carlens catheter surmounted all these difficulties. The relative merits of these various catheters and the general aspects of the subject are fully reviewed in a series of papers by Gaensler and various collaborators (Gaensler, 1952, 1953 ; Gaensler and Cugell, 1952a and b; Gaensler and Watson, 1952 ; Gaensler, Maloney, and Björk, 1952 ; Gaensler, Patton, and
Frank, 1953 ; Gaensler, Watson, and Patton, 1953). Gaensler (1953) also analyses the results of 1,000 such investigations using various of the catheters mentioned. This paper reports the study of 125 cases investigated using the Carlens catheter, and makes no mention of many previous studies made at this hospital using the earlier types of catheter. Marsh (1953) and Croce (1954) each describe catheter designs which they claim to be superior to the Carlens. We have no experience of these catheters, but have not found the Carlens catheter to have the defects which they ascribe to it.

\section{Apparatus}

The Carlens catheter has been fully described elsewhere (Carlens, 1949; Gaensler, 1952 ; Gaensler and others, 1952). The catheters (Fig. 1) as supplied for the male and the female were used in the specified sex unless there was some special reason to believe that the other catheter would provide a better fit. It was commonly found that the catheters on delivery have cuffs which are hot sufficiently distensible and this is remedied by maintaining them inflated at a suitable pressure for some weeks before use.

The spirometer assembly (Fig. 2) consists of twin spirometers in closed circuits of the Knipping type, with soda lime absorption of the carbon dioxide and mixing within the circuit carried out by rotary pumps. The spirometer bells are of such dimensions that a movement of $1 \mathrm{~cm}$. on the paper indicates a change of volume of $100 \mathrm{ml}$. This gives a light weight bell and a trace with a good excursion on quiet breathing. Pure oxygen was used in the circuits. The criticism has been made of this (Gaensler and Cugell, 1952a) that it may obscure defects of function, but in our cases we did not feel this caused errors of any practical significance.

Each circuit is also fitted with the necessary accessories so that helium mixing runs by the 


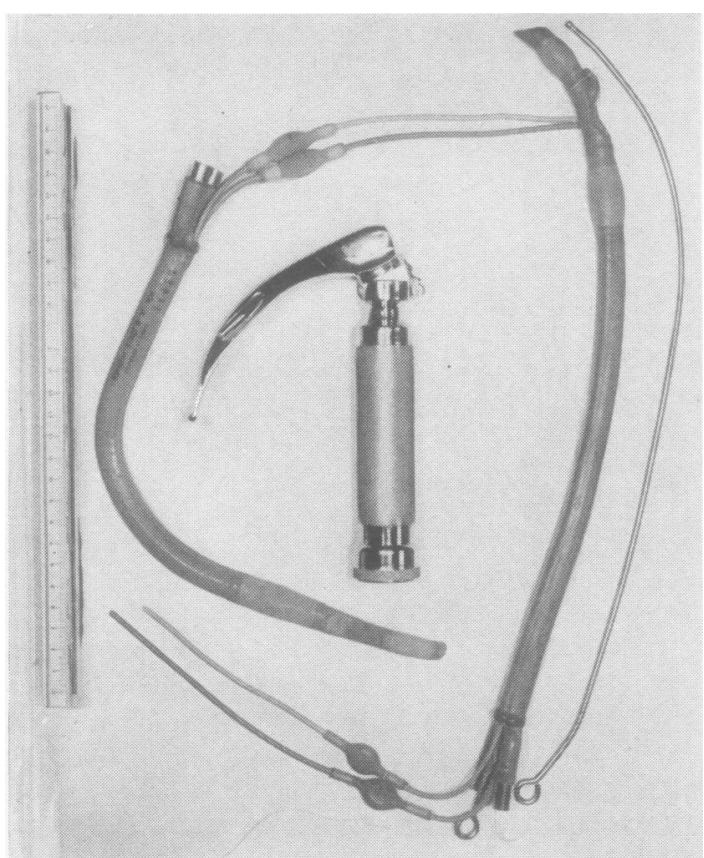

Fig. 1.-Carlens's catheter and the laryngoscope. On the right is an introducer and a male catheter with the carinal hook tied down and the introducer inserted ready for placing in the trachea. The orifices of the two airways, the hook, and the cuffs can be plainly seen. On the left is a female catheter without the introplainly seen. On the left is a female catheter without the intro-
ducer, showing the shape assumed when the catheter is positioned in the trachea.

method of McMichael (1939) may be carried out on the two lungs simultaneously.

The twin spirometers write one above the other on the same drum where pens also mark off the time intervals and signals (Figs. 2 and 3 ).

\section{Procedure}

In all cases a postero-anterior (P.A.) radiograph of the chest was inspected and, wherever possible, a bronchogram or P.A. tomogram of the trachea and major bronchi. These latter are of assistance in demonstrating deformities and the length of the left main bronchus and in allowing the degree of inflation of the cuffs necessary to block off the air passage to be assessed.

Preparation.-The tests were done in the morning, the patient having had nothing by mouth since an early morning cup of tea. Premedication was with omnopon gr. 1/3 and scopolamine gr. 1/150, the dose being reduced in people of small stature or where there was any other indication. It was given hypodermically three-quarters of an hour before the test. A quarter of an hour beforehand, the patient was given a one-grain tablet of amethocaine to suck. The general procedure hade been previously explained to the patient and throughout the subsequent manipulations, especi- $\frac{\text { क }}{\sigma}$ ally the intubations, a low-toned series of explana $\unrhd$ tions and reassurances is maintained. This is most important in ensuring the maximum degreeof relaxation and co-operation. Children wereinvestigated with combined local and generatw anaesthetic.

LOCAL ANAESTHESIA.- No more than $4 \mathrm{ml}$. ofe $1 \%$ amethocaine is used. For this cotton woolp pledgets on Krausser forceps are placed in each pyriform fossa in turn and on the upper surface of the epiglottis. The patient then lies down on? a padded trolley and $0.25 \mathrm{ml}$. of $1 \%$ amethocaine is injected into the trachea between the first ando second cartilages. The patient then sits up ando coughs. Under direct vision with the aid of क्ष Mackintosh laryngoscope, a gum elastic catheter: stiffened in ice, is put through the glottis; the patient is then rolled to each side in turn and $0.5 \mathrm{ml}$. of $1 \%$ amethocaine injected into each main bronchus.

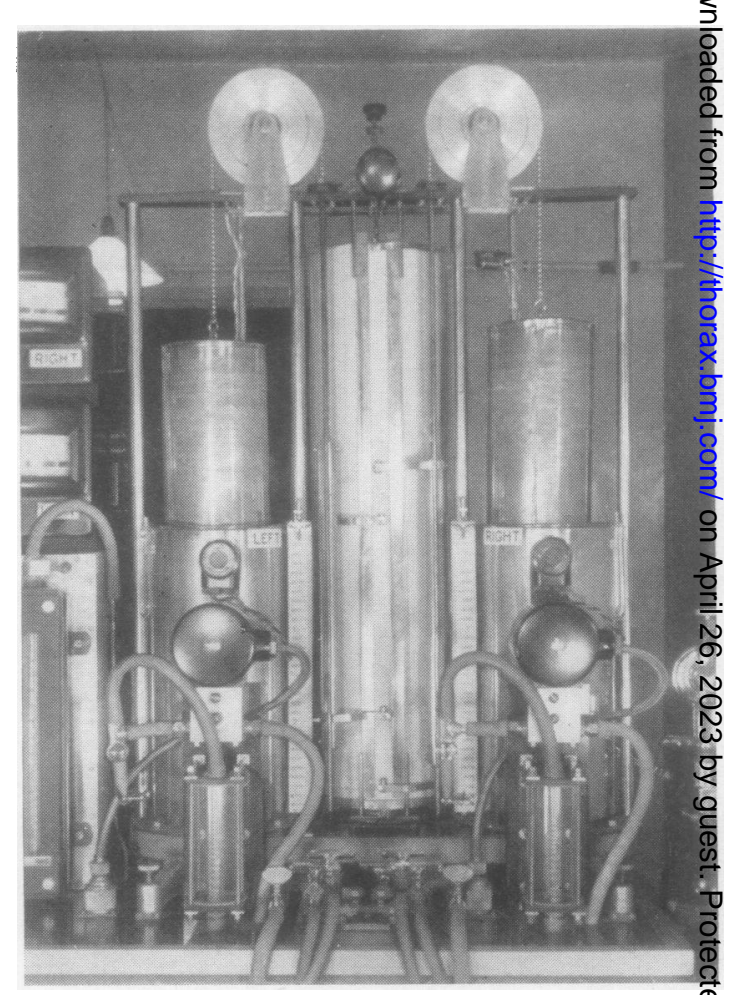

FIG. 2.-Twin spirometer assembly. The movements of the righ and left lungs are transmitted to the two spirometers and the tracings recorded one above the other on the central drune In front of the spirometers are the twin katharometers and on the left, the galvanometers linked with these. 
The Carlens catheter is then prepared for use. The two cuffs are inflated and the desired size is judged by matching on a bronchogram or tomogram. The pressure required is noted on a mercury manome er incorporated in the apparatus. The carinal hook is tied down with a moistened thread, the introducer inserted (Fig. 1) and tested for free movement, and the whole lubricated with cold water. The laryngoscope is again introduced to give a full view of the glottis, and as it opens on inspiration the Carlens catheter is quickly introduced, the laryngoscope being retained until the hook is through the cords. The introducer is then removed and the hook released by a sharp pull on the thread.

At this stage a small bout of coughing is usual, but quickly subsides if the catheter is not moved in the trachea. The trolley is then wheeled to the twin spirometer assembly, the inflating tubes are connected to the cuffs and the catheter finally positioned. This is remarkably easy, as the moulding of the catheter gives it a strong tendency to adopt the correct position after the introducer has been removed (Fig. 1). As the catheter is advanced down the trachea, the simultaneous appearance of a characteristic sense of resistance and a bout of coughing are good evidence that the hook has engaged the carina. The catheter is held in position and the cuffs are in turn inflated to the predetermined pressure. During this process, the ear is kept close to the catheter mouth to detect any wheeze or change in the air flow suggestive of obstructing an airway. The patient is then connected to the spirometer system with the taps turned so that he breathes into the atmosphere. At the end of an expiration the taps are then turned so that he breathes into the spirometer circuit.

After a few breaths, the appearance of the trace on the drum will confirm that the catheter is in the correct position and the cuffs properly inflated. Various patterns (Wright and Michelson, 1950) of trace from incorrectly placed catheters are easily recognized. If these are seen the cuffs are deflated and the catheter repositioned or the cuffs blown up more tightly as necessary. It is most unusual for the first placing of the catheter not to be the correct one.

With this régime, catheters could be kept in position without upset to the patient for 30 minutes or more. In the usual test, much less time than this was necessary. The total time needed for the entire procedure for a single test is no more than 20 minutes, and we have found it most efficient to do them in batches of five, if the cases were available.

Maximum breathing capacities are determined in all cases before bronchospirometry. The method uses a simple spirometer with an electromagnetic counting device that adds up the volumes displaced. The best of three readings is taken as the result, though more are done if these are not close to one another. The spirometer used will be shortly replaced by one made according to the design of Bernstein, D'Silva, and Mendel (1952) with an interrupted light beam used in the counting device.

Method of Follow-UP. - The first 50 cases had to be followed up in retrospect. Their case notes and radiographs were obtained and the requisite clinical details abstracted, and questionnaires were sent out to the patient and his doctor. These enquired about the value of the results obtained from the investigation, and any subsequent deterioration in the patient or his radiograph. Specific enquiry was made for the following symptoms in the days after the investigation : hoarseness, sore throat, difficulty in swallowing, haemoptysis, fever, bronchospasm, or any other symptoms. These are the symptoms stated to occur in other series (Gaensler and Watson, 1952). It was suggested that any symptoms on the day of the test be ignored.

The patient was asked to state frankly whether he would be willing to undergo the investigation again, and to list in order of preference a visit to the dentist, bronchospirometry, bronchography, and bronchoscopy, or such of these as he had experienced. Some patients found the detailed reply to this last question beyond them, and covered the situation with a general statement such as, " I didn't mind at all," which we cannot include in the figures we analyse (Table V). The aim of this question was simply to provide a standard of comparison with other experiences commonly undergone by patients with chest disease.

In the case of the later investigations, the questionnaires were sent out two weeks after the test, but sufficient liaison was by then established for any later complications to be reported.

It should be explained that all the bronchoscopies and bronchography are carried out by a highly experienced group of workers with considerable efficiency. The method used for bronchography involves the placing of a small gum elastic catheter in the trachea using direct laryngoscopy under local anaesthesia. Watery "dionsil" is used routinely. With this method, used in over 1,000 tuberculous cases at this 
hospital, there have been no complications other than minor ones.

\section{Patients}

Patients come from a number of hospitals and clinics throughout South Wales. Those who were not patients at Sully Hospital were investigated as out-patients.

In the case of the first 90 patients, the investigations were carried out with specific surgery in mind, and the information given by the test was thought desirable (before the operation was proceeded with) by the physicians and surgeons in charge of the case. After these 90 cases the results had been found so encouraging that it was considered to be justifiable to investigate definite problems on a series of volunteers. The following details give a picture of the types of cases investigated in this series.

\section{Diseases InVESTIGATED}

Table I shows the diseases investigated:

TABLE I

\section{DISEASES INVESTIGATED}
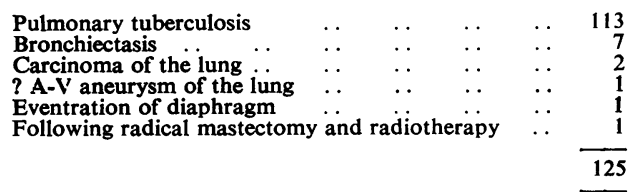

Of the tuberculous cases, Table II shows previous treatments that may reduce function.

\section{TABLE II}

TREATMENTS POSSIBLY REDUCING FUNCTION

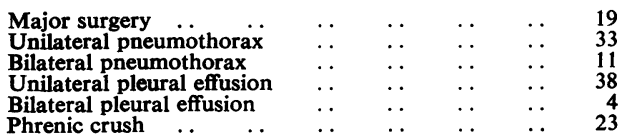

Of the 19 cases of major surgery, eight were investigated in respect of problems not actually related to that individual patient in order to study functional results after segmental resection.

Of the pneumothoraces, $23(42 \%)$ had been complicated by effusion of a gross nature.

Table III enumerates the incidence of findings that may be thought to lead to complications after bronchospirometry.

TABLE III

SPUTUM STATE, ETC.

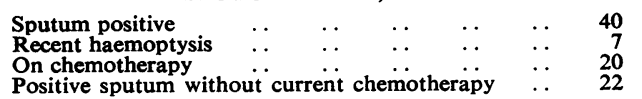

The cases were nearly all in a quiescent phase $\bar{C}$ of the disease, and ready for major surgery. Most of them were hospital in-patients and were on bed $\frac{\bar{\omega}}{\vec{T}}$ grades. Seventeen of them were on absolute rest. $\stackrel{\mathbb{Q}}{\stackrel{D}{ }}$

\section{DYSPNOEA}

Dyspnoea was difficult to evaluate in such $\stackrel{\overrightarrow{0}}{-}$ patients who had no opportunity of testing them- $\vec{\omega}$ selves, but the following classification indicates the degrees of dyspnoea claimed.

$\begin{array}{lllr}\text { Slight .. } & \ldots & \ldots & 27 \\ \text { Moderate } & \ldots & \ldots & 12 \\ \text { Marked .. } & \ldots & \ldots & 1\end{array}$

AgEs.-The ages ranged from 11 years to $65-$ years, but the majority of the patients were young adults between the ages of 20 and 35 years. With the catheter available, 11 must be regarded as the 3 earliest possible age for this investigation, as in this case the female catheter was quite a tight fit $\vec{\theta}$ in the left main bronchus.

SEx.-There were 49 women and 76 men. was soon recognized that women were much more easily intubated than men. This was felt to bes partly due to anatomical factors, but chiefly too women's ability to relax and co-operate in the face $\frac{}{\mathbb{D}}$ of some discomfort. This virtue of the female $\stackrel{\varrho}{\rightarrow}$ sex is also very evident in the post-operative ward. $\overrightarrow{0}$

Most of the patients came from a small number 3 of institutions, and had been suitably prepared for the investigation by those of their colleagues whohad had the distinction of being previous subjects. Not unnaturally the latter had made the most of the experience that distinguished them from their. fellows and, in spite of our explanations before the 3 test, most of the patients were very pleasantly surprised at the little discomfort they suffered, and volunteered that their apprehension was much the worst feature of the test.

\section{RESULTS}

In all except one case, the quality of the tracingo was such that useful information could be readily obtained. In this case, of a woman, the diameterN of the trachea was such that the cuff of the female ${ }_{\sigma}^{\omega}$ catheter would not fill it and yet the larynx was too small to allow the entry of the male catheter. A successful tracing was later obtained using a@ female catheter fitted with a larger cuff.

The quality of the tracings usually differed little (Fig. 3) from those obtained in ordinary spirometry, and the base line was smooth in most cases. $\frac{\text { के }}{\circ}$ Periodic breathing due to omnopon, and usually following on a period of over-breathing, sometimes? 


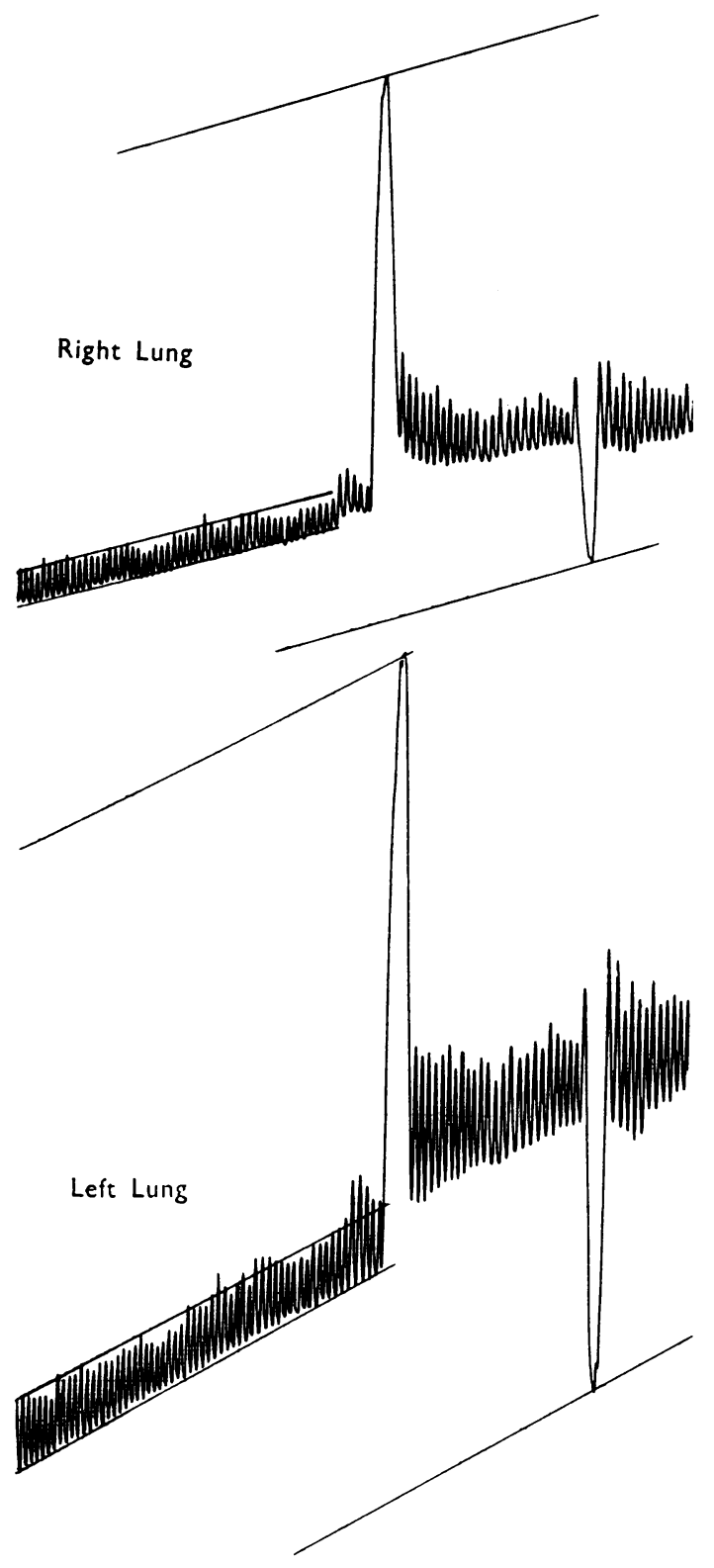

TIME IN MINUTES

\begin{tabular}{|c|c|c|c|}
\hline & & Right Lung & Left Lung \\
\hline $\begin{array}{l}\text { Oxygen uptake } \\
\text { Ventilation } \\
\text { Vital capacity }\end{array}$ & $\begin{array}{l}\ldots \\
\cdots\end{array}$ & $\begin{array}{l}83 \mathrm{ml} . / \min .(30 \%) \\
1.881 . / \mathrm{min}_{.}(30 \%) \\
1.15 \mathrm{l} .(37 \%)\end{array}$ & $\begin{array}{l}187 \mathrm{ml} / \mathrm{min} .(70 \%) \\
4.51 . / \min .(70 \%) \\
1.961 .(63 \%)\end{array}$ \\
\hline
\end{tabular}

FIG. 3.-Case 111. causes an irregular tracing, but such patients are usually so somnolent that 10 minutes or more of tracing can be taken and a base line drawn for the whole period (Fig. 4). Coughing rarely caused disturbance to the tracing in the initial phases, though cough was sometimes initiated by the too rapid measurement of the expiratory reserve capacity. In such cases, the return of the tracing to the base line gives added confidence that there is no leak around the cuffs.

Maximum Breathing CapaCity.-Maximum breathing capacities ranged from 23 to 1701 ./ min., and there were seven cases with capacities below $40 \mathrm{l} . / \mathrm{min}$. Patients with low results showed no more distress than the others.

Tracheal Deformity.-Tracheal deformity was often quite marked, but in no case did it provide any difficulty to the straightforward insertion of the catheter. In 13 cases this was graded as marked (Figs. 5 and 6), in 13 as moderate, and in 31 cases as slight. Bronchograms are very helpful in these cases, particularly in giving information about the length of the left main bronchus and thus about the situation of the cuff.

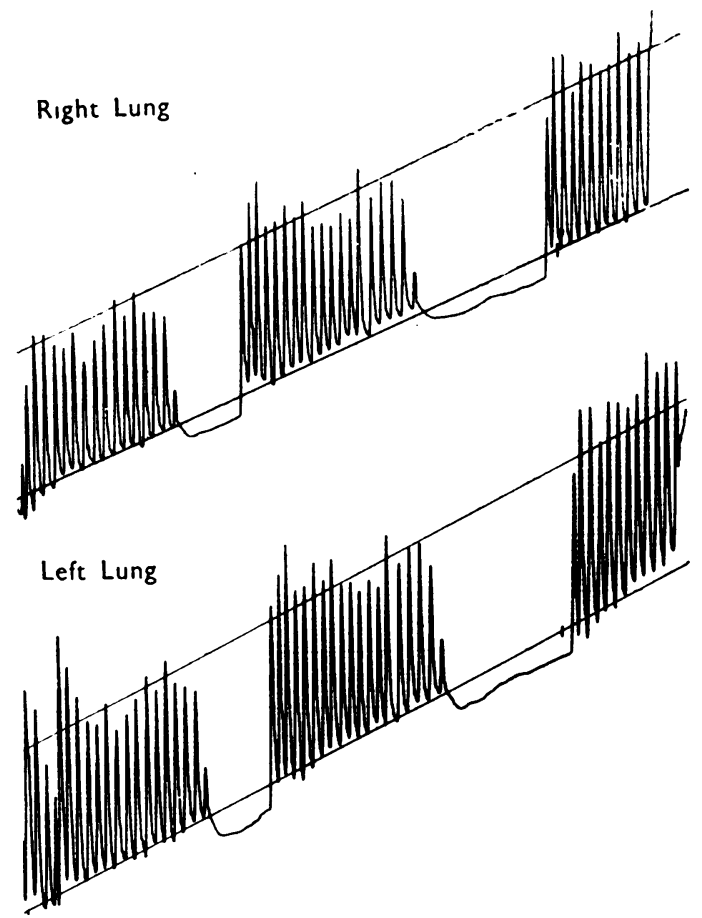

Fig. 4.-Tracing of Case 63, man aged 42 , showing periodic breathing after omnopon, grains $1 / 3$. 

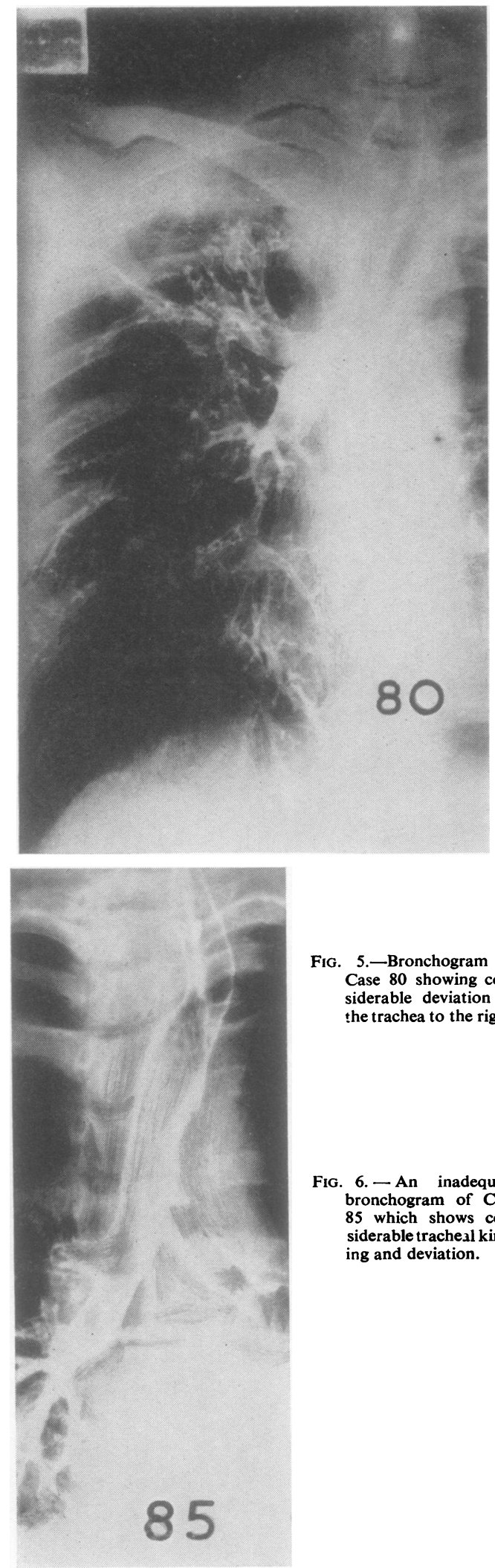
ing and deviation.

\section{Observations Made}

After the first few breaths the resting respiratory level would stabilize and the patient was allowed to breathe quietly until four or more minutes of $\stackrel{\mathbb{Q}}{\Omega}$ good quality tracing had been obtained. It was then usual to get separately several records of the $\vec{\circ}$ inspiratory capacity and the expiratory capacity. Measurements of M.B.C. were not usually done $\vec{\omega}$ with the catheter in position. The percentage figure obtained for such results always agreed so $\vec{x}$ closely with the percentage of the resting minute 6 ventilation that it was soon felt that these further steps were superfluous (see Björkman and Carlens, 1951 ; Inada, Kishimoto, Satô, and Watanabe, 1954).

In special cases, helium mixing curves were $\vec{\nabla}$ carried out in the two lungs simultaneously. This $\mathbb{D}$ was of particular interest where unilateral emphy- $\mathbb{\mathscr { T }}$ sema was suspected.

\section{Normal Values}

Experience with a small series of near normal cases and of normals investigated using other catheters has led us to accept the values of Baldwin, Cournand, and Richards (1948). These are that $55 \%$ of the total function of both oxygen uptake and ventilation is found in the right lung. $\mathbb{\perp}$ Due to the departure from basal conditions, we $\vec{\overrightarrow{ }}$ express all our results only as a percentage of the $\frac{3}{3}$ total function and take no note of the absolute $\bar{P}$ values found during the test. Overall absolute values can be more reliably measured using both lungs.

Fig. 5.-Bronchogram of Case 80 showing considerable deviation of the trachea to the right.

FIG. 6. - An inadequate bronchogram of Case 85 which shows considerable tracheal kink-

\section{RESULTS}

Slopes were drawn on the tracing (Fig. 3, etc.) and the oxygen uptake and average tidal air measured. The ventilation was then obtained by multiplying the tidal air by the rate of breathing. The values are in all cases expressed as a percentage of the total function. These values were $\frac{7}{0}$ frequently in close accord, especially considering the relative inaccuracy of the ventilation measure- $\sigma$ ment.

In $52.5 \%$ of cases, the percentage values for $N$ oxygen uptake and minute ventilation were within $\omega$ 5 of each other, and in another $32.5 \%$ they agreed to between 5 and 10 . Vital capacities were similarly in close agreement with the other figures. $\stackrel{\mathcal{D}}{\rightarrow}$ A notable exception is provided by an "expanded "? pneumothorax where the oxygen uptake is commonly much less than the ventilation. This in- $\vec{\Phi}$ dicates a diminished circulation in the pulmonary $\frac{}{\mathrm{D}}$ arteries on that side, and is especially marked in $\frac{2}{O}$ recently abandoned pneumothoraces. 
In bronchiectasis, there is a consistently similar finding (Long, Norris, Burnett, and Wester, 1950), though in the cases investigated it was less marked than in the pneumothorax cases.

\section{SeQuelae}

On the day of the test it was usual for the patient to have a slightly sore throat, especially on swallowing, and some hoarseness. To diminish this, it was suggested that whispers only be used during that day. The occasional patient coughed up a little blood-stained secretion immediately after the test. Most patients were content to spend much of the day sleeping after their premedication.

Table IV shows the symptoms and signs reported in the days following the day of the test.

\section{TABLE IV}

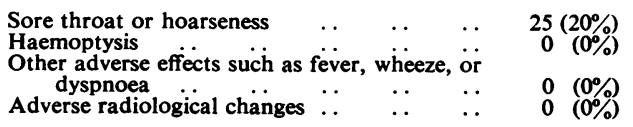

In every case, the sore throat was described as a slight discomfort, particularly on swallowing, and in no case was it severe enough to be called unpleasant. It usually lasted for only one day, but three patients described it as lasting as long as three days. No adverse radiological changes following the test were reported.

Thus, apart from the inconvenience of the sore throat for a short period in just $20 \%$ of cases, there is no evidence that bronchospirometry is in any way a harmful procedure.

\section{Patients' Reactions}

The questionnaire previously described was eventually returned in all cases, but the final question, asking the patient to put in order of preference the experiences of bronchography, bronchoscopy, bronchospirometry, and a visit to the dentist, was satisfactorily answered in only 105 cases. From our records we know that in the 125 cases, 88 patients had had bronchography, 33 bronchoscopy, and 29 both. Of the 105 replies, 61 (49\%) patients gave bronchospirometry as their first choice and one patient actually claimed to be much improved after the investigation!

A simple method of scoring was used in an attempt to illustrate the relative popularity of these experiences; the first choice was given the score of 1 , the second 2 , etc. In most cases the score went up to 3 , but only in those cases where bronchoscopy was included did it reach 4 . This gives somewhat of a bias against bronchoscopy, but is more useful in the other cases, particularly with reference to the dentist, who is considered in the same number of cases as bronchospirometry. The total score for each experience was added up and divided by the number of scorers to give an average score (Table V).

TABLE V

RELATIVE POPULARITY OF PROCEDURES

\begin{tabular}{|c|c|c|c|}
\hline Procedure & & $\begin{array}{l}\text { Average } \\
\text { Score }\end{array}$ & $\begin{array}{l}\text { No. of } \\
\text { Scorers }\end{array}$ \\
\hline $\begin{array}{l}\text { (1) Bronchospirometry } \\
\text { (2) Visit to the dentist } \\
\text { (3) Bronchography } \ldots \\
\text { (4) Bronchoscopy } \ldots\end{array}$ & $\begin{array}{l}\cdots \\
\cdots \\
\cdots\end{array}$ & $\begin{array}{l}1 \cdot 53 \\
1 \cdot 80 \\
2 \cdot 00 \\
2 \cdot 94\end{array}$ & $\begin{array}{r}105 \\
105 \\
78 \\
32\end{array}$ \\
\hline
\end{tabular}

As lowness of score indicates degree of popularity, bronchospirometry clearly comes out of this examination as a much less fearful procedure than other experiences which are commonly recommended with little thought for their discomfort.

One hundred per cent. of the patients expressed their willingness to have the test repeated if necessary, and many qualified this with a comment such as, "There's nothing to it." That this is no empty boast is borne out by the fact that seven of the patients in this series were undergoing bronchospirometry for the second time, and one for the third time. Fourteen of the cases were patients in Sully Hospital who voluntarily submitted to the test clearly knowing the nature of the test and that there was no possibility of personal benefit.

\section{Value of THE Test}

In every case we were able to give a clear report on the findings. Also in every case the doctor concerned reported that he had found the information supplied of value in the assessment of the case.

\section{Illustrative Cases}

These are chosen to illustrate some of the problems dealt with. They are not meant to be a study in themselves, and it is hoped in the future to publish a more detailed study of collected cases of similar problems. The brief details given are intended to supply essential information in the functional background of the cases only, and in no way give a full clinical picture of the cases or of the other matters of importance in deciding on the best form of treatment.

The cases do not include any with the gross losses of function that would be obvious without this investigation. Thus we do not present any 
dramatic tracings showing one lung doing almost all the work.

CASE 111.-D. S., a man aged 39 years, in November, 1953, experienced the onset of general symptoms and of dyspnoea on exertion. A radiograph showed extensive old tuberculous disease on the right side with recent spread and cavitation. After treatment in bed with chemotherapy and postural retention the cavities closed (Fig. 7). Bronchography confirmed that there was extensive disease in the right lung with destruction of the right upper lobe and the apical segment of the lower lobe. The M.B.C. was $100 \mathrm{l} . / \mathrm{min}$. It was considered necessary to know the function remaining on the right side so that the information was available if the question of pneumonectomy should have to be considered at thoracotomy. Bronchospirometry (Fig. 5) with $30 \%$ of the function on the right side showed that, from a functional point of view, right pneumonectomy was possible though not desirable.

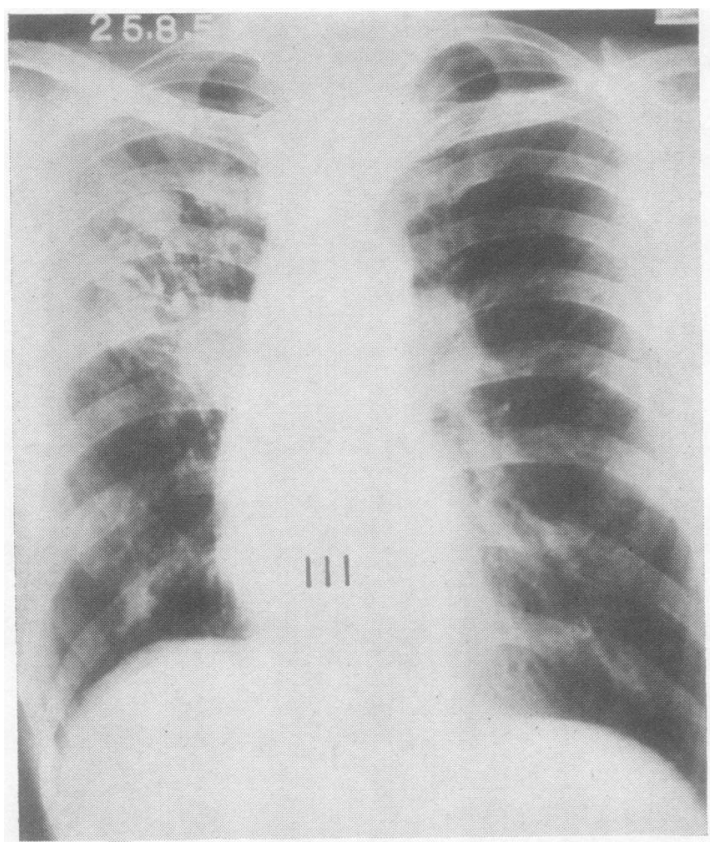

FIG. 7.-Postero-anterior radiograph of the chest of Case 111 showing extensive tuberculous disease of the right lung. The bronchospirometric record of this case is shown in Fig. 5.

CASE 100.-T. H. E., a boy aged 11 years, in January, 1954, had an acute right-sided pleural effusion, which was treated by bed rest and antibiotics, and in July, 1954, the appearances were as in Fig. 8. Physical signs were definite but not gross. No parenchymal disease was demonstrated by tomography or bronchography. Bronchospirometry (Fig. 9) was carried out under general anaesthesia. This shows that the right lung is performing only $27 \%$ of the oxygen uptake and $33 \%$ of the ventilation. This was taken as a strong indication that decortication should be carried out.

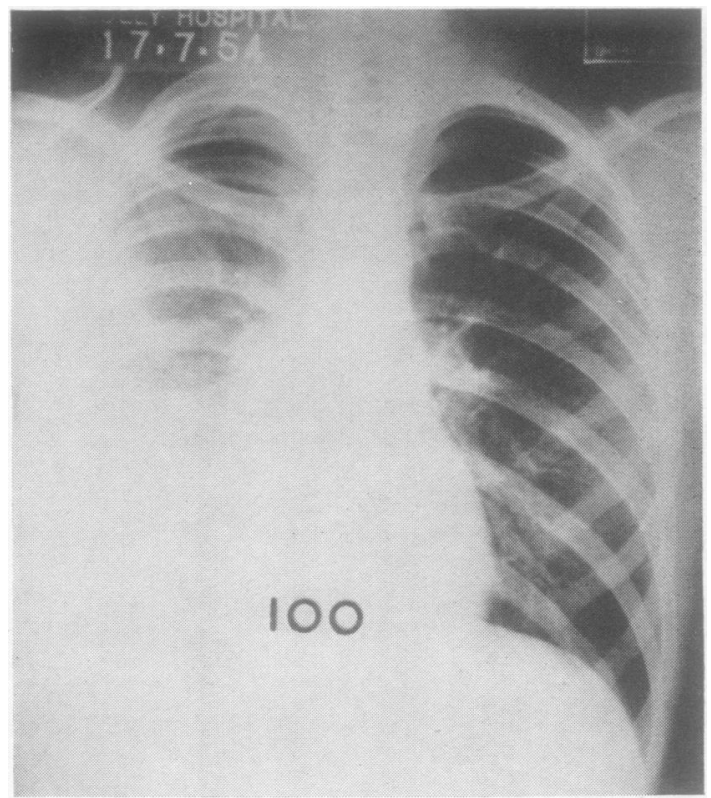

FIG 8-Postero-anterior radiograph of Case 100 taken six months after the onset of the right pleural effusion. The bronchospirometric record of this case is shown in Fig. 9.
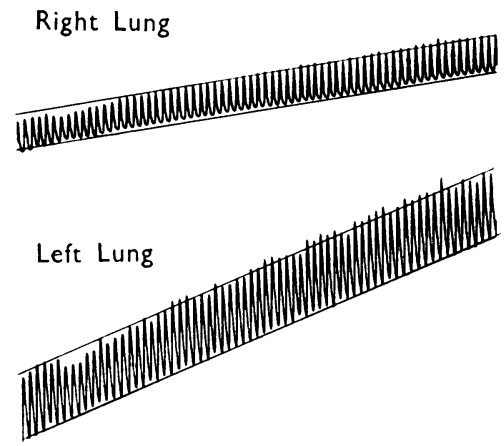

TIME IN MINUTES

\begin{tabular}{|c|c|c|}
\hline & Right Lung & Left Lung \\
\hline $\begin{array}{l}\text { Oxygen uptake } \\
\text { Ventilation }\end{array}$ & $\begin{array}{l}50 \mathrm{ml} \cdot \min .(27 \%) \\
1.61 . \min .(33 \%)\end{array}$ & $\begin{array}{r}135 \mathrm{ml} \cdot \min .(73 \%) \\
3 \cdot 21 . \min .(67 \%)\end{array}$ \\
\hline
\end{tabular}

FIG. 9.-Tracing of Case 100 (bronchospirometry under general anaesthesia). 
CASE 102.-R. M., a woman aged 37 years, five years before had a left radical mastectomy for carcinoma. This was followed by a course of deep $x$-ray therapy. She now has an unstable, large, solid tuberculous lesion in the right upper lobe (Fig. 10). She has moderate dyspnoea on exertion, and the left chest is encased in dense scar tissue which permits very little movement. The M.B.C. is $751 . / \mathrm{min}$. In addition to the mechanical aspects of the matter it was thought likely that the radiotherapy had damaged the left lung and that resectional surgery on the right would not be possible. Bronchospirometry showed an almost normal distribution of function, with $41 \%$ of the oxygen uptake and $50 \%$ of the ventilation on the left. It was thus felt that surgery could be planned for the lesion on the right.

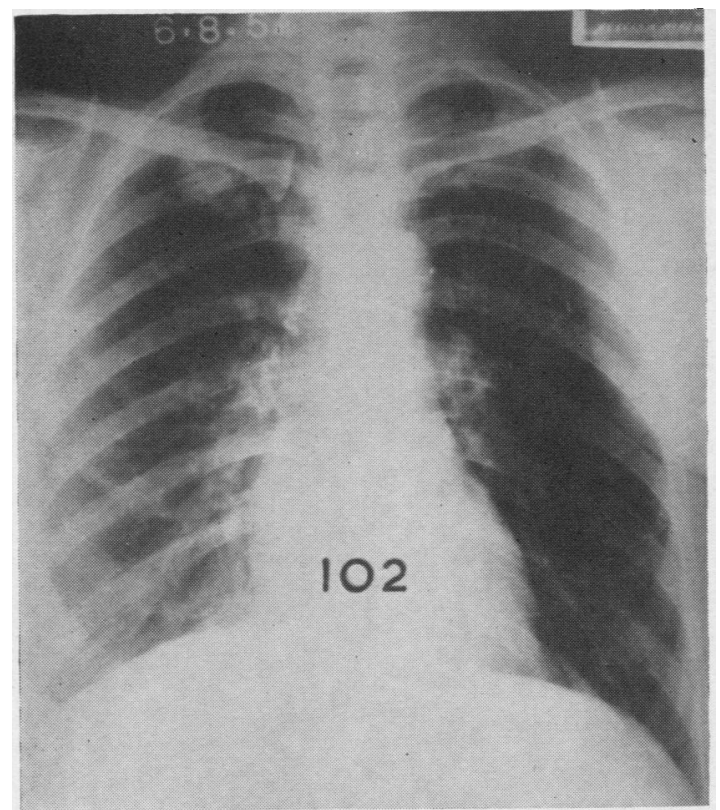

FIG. 10-Postero-anterior radiograph of Case 102 showing a solid tuberculous lesion in the right upper lobe and the relative translucency of the left chest due to the radical mastectomy.

CASE 68.-A. G., a man aged 57 years, in 1917 received a gunshot wound of the left chest. This was followed by empyema and a sinus which continued to discharge till 1924. In 1953 he began to notice some shortness of breath on exertion, and in February, 1954, he had a radiograph which showed a rounded lesion in the right upper lobe. Although all other investigations proved negative, this was presumed to be a carcinoma (Fig. 11). The M.B.C. was $74 \mathrm{l} . / \mathrm{min}$., and it was doubted whether, in view of his previous history, he would stand even a lobectomy. Bronchospirometry showed an oxygen uptake of $40 \%$ on the left side and a ventilation of $46 \%$. Thoracotomy was performed, and a carcinoma was completely removed by a right upper lobectomy. His dyspnoea was not significantly worse.

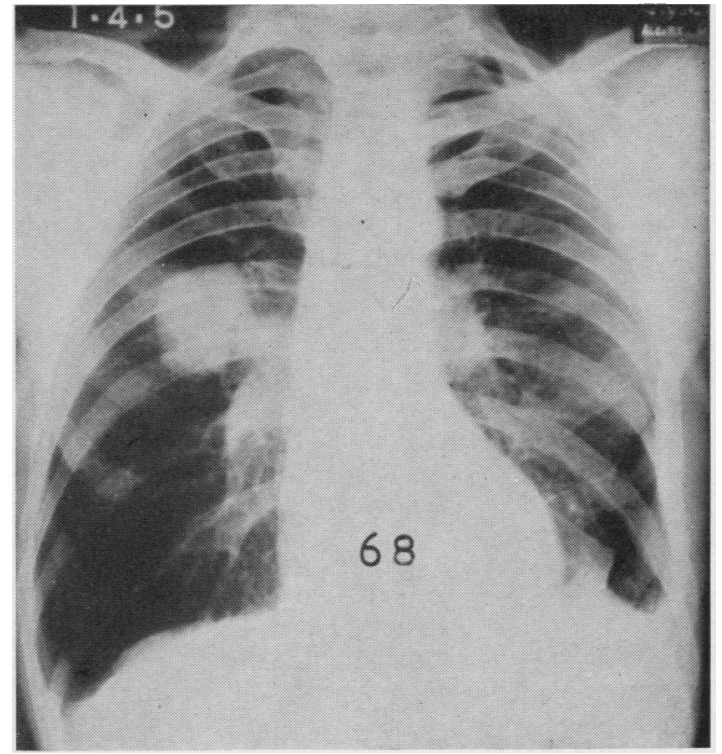

FIG. 11.-Postero-anterior radiograph of Case 68 showing the carcinoma in the right upper lobe and evidence of the old left empyema. A metallic foreign body is concealed behind the heart shadow.

CASE 80.-J. E. M., a man aged 27 years, had bilateral disease dating from 1942 . In 1950 he had a right phrenic crush followed by a pneumoperitoneum, and in January of 1951 a left artificial pneumothorax was induced. In October, 1953, this was abandoned because of fluid. The fluid absorbed quite well (Fig. 12), and the right-sided disease was considered

FIG. 12.-Postero-anterior radiograph of Case 80 showing tuberculous disease in the right upper lobe (better seen in the bronchogram in Fig. 5) and the state of the old left artificial pneumothorax. The bronchospirometric record of this case is shown in Fig. 13. The function of the left lung $(50 \%)$ has been less reduced than that of the right lung (cf. Fig. 15).

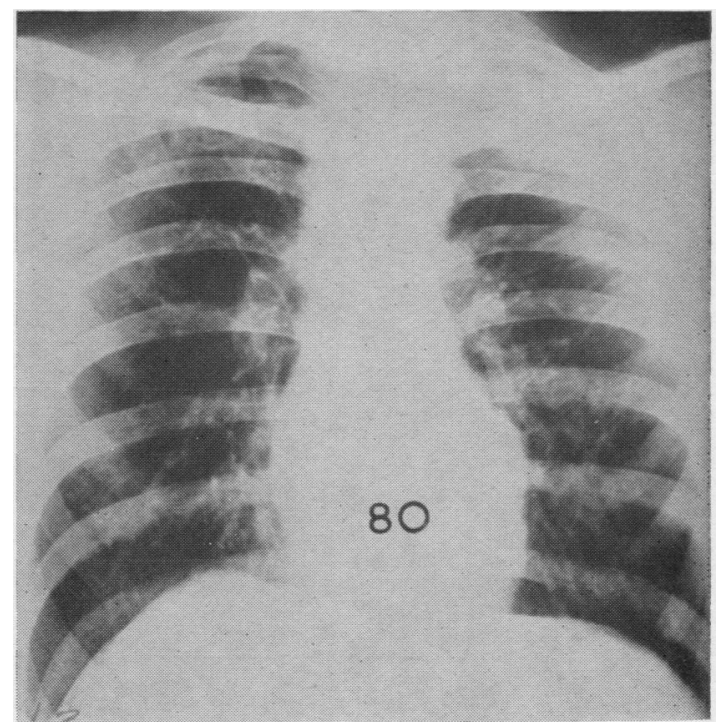


to be the major problem. It was desirable to know whether there was sufficient function on the left side to allow resection to be carried out on the right without first doing a decortication on the left. The M.B.C. was $921 . / \mathrm{min}$. Bronchospirometry (Fig. 13) showed that the functions of the two lungs were equally divided, and therefore the right side was treated without delay.

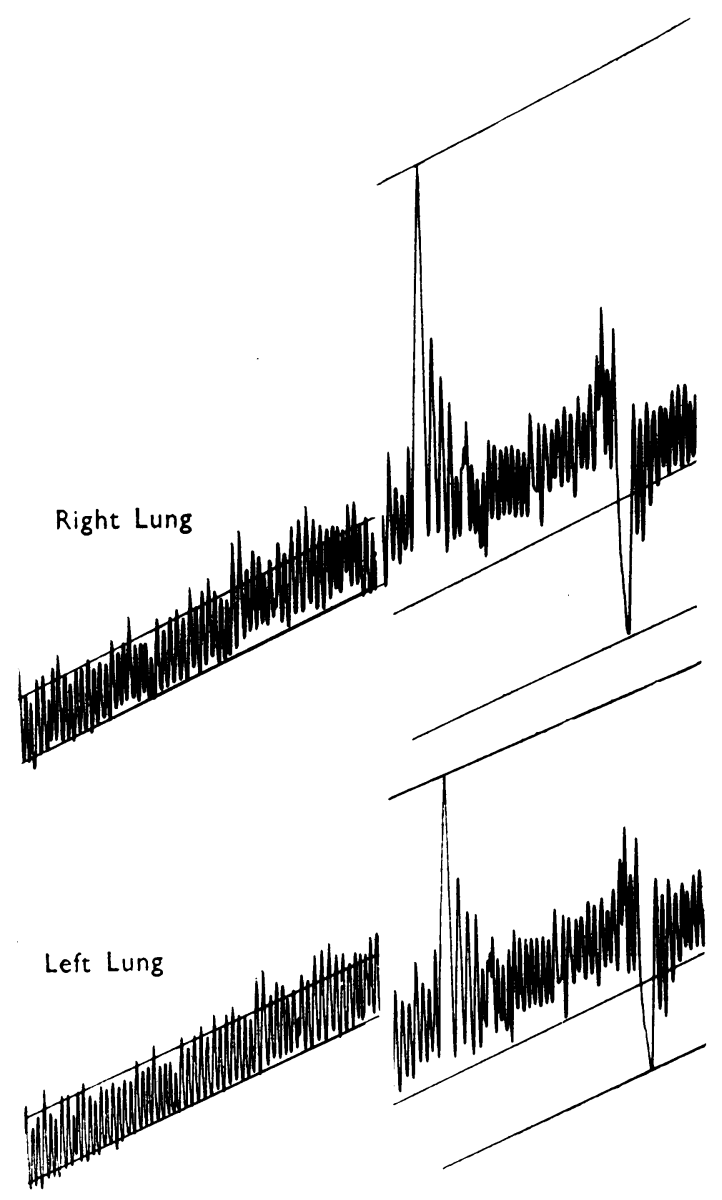

TIME IN MINUTES

\begin{tabular}{|c|c|c|c|}
\hline & & Right Lung & Left Lung \\
\hline $\begin{array}{l}\text { Oxygen uptake } \\
\text { Ventilation } \\
\text { Vital capacity }\end{array}$ & $\begin{array}{l}\cdots \\
\cdots \\
\cdots\end{array}$ & $\begin{array}{l}150 \mathrm{ml} . / \min .(50 \%) \\
3.01 . / \min .(50 \%) \\
1.271 .(60 \%)\end{array}$ & $\begin{array}{c}150 \mathrm{ml} . / \mathrm{min} .(50 \%) \\
3.01 . / \mathrm{min} .(50 \%) \\
0.8501 .(40 \%)\end{array}$ \\
\hline
\end{tabular}

Fig. 13.-Tracing of Case 80.
CASE 20.-M. J., a girl aged 15 years, in February of 1953 had a sudden left pleural eifusion. In spit产. of bed rest this persisted until July of the same yea (Fig. 14). Clinically and radiologically the function on the left side did not appear to be good, buछ bronchospirometry showed that the oxygen uptakewas $46^{\circ}$ and the ventilation $48^{\circ}$. The M.B.C. was? $921 . / \mathrm{min}$. No parenchymal disease was demonstrable $\overrightarrow{\vec{c}}$ and it was felt that decortication was not indicated

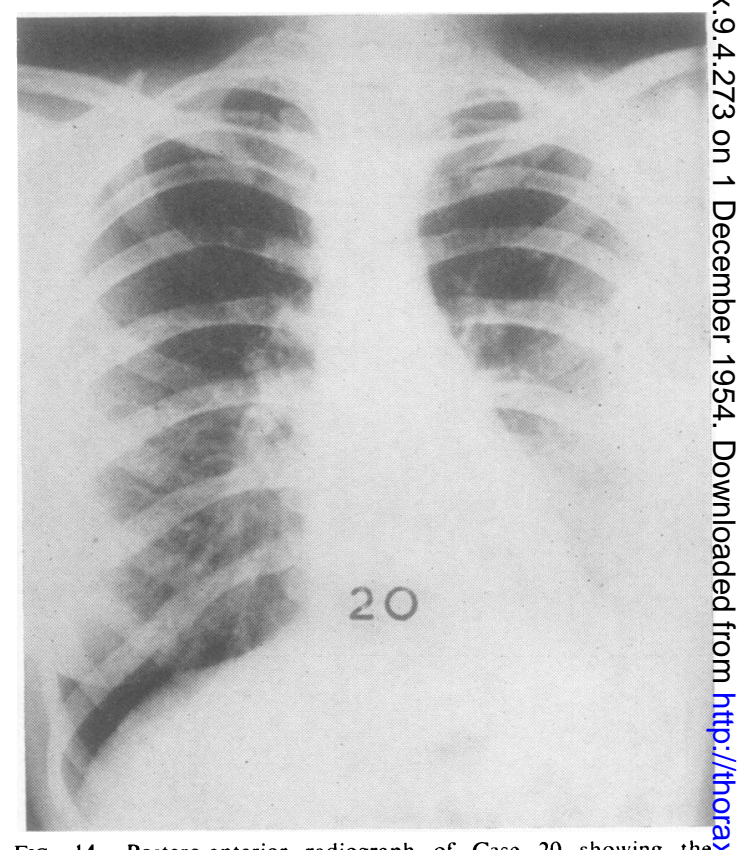

FIG. 14.- Postero-anterior radiograph of Case 20 showing the appearances six months after the onset of a left pleural effusion. The function of the left lung is normal (cf. Fig. 15).

CASE 5.-N. C., a woman aged 28 years, haßs general symptoms in 1946. In 1947 tuberculosis with cavitation in the left upper lobe was diagnosed, anc in January, 1948, a left artificial pneumothorax was induced. At adhesion section in March of the same year there was considerable haemorrhage and the artin ficial pneumothorax was abandoned. In June a lef $P$ phrenic crush was performed. She kept reasonably well until October, 1952, when she had a haemoptysisN Investigation showed that the left side was in reason $-\bar{\sigma}$ able condition, but there was now cavitated disease in the right upper lobe. In January, 1953, this ha\& regressed to the point shown in Fig. 15, and the question of surgery was considered. It was felt important to know what loss of function there hado been on the left following the artificial pneumo thorax. The M.B.C. was $641 . / \mathrm{min}$. Bronchospiro metry on February 11, 1953, showed an oxygen up $\overrightarrow{\mathbb{D}}$ take of only $28 \%$ on the left and ventilation of $39 \%$ A Holst thoracoplasty was carried out on the right side. 


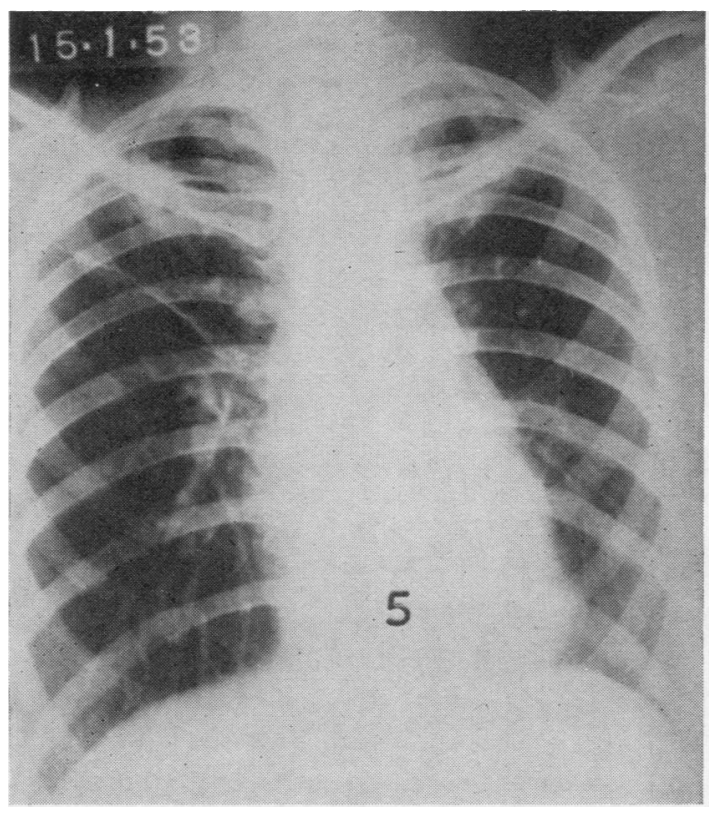

FIG. 15.-Postero-anterior radiograph of Case 5 showing tuberculous disease of the right upper lobe. The appearances of the left lung, following an artificial pneumothorax, are relatively normal (cf. Figs. 12 and 14), but bronchospirometry showed the function to be considerably reduced.

CASE 86.-M. T., a woman aged 31 years, had had various treatments since 1949 for tuberculosis of the left upper lobe. In July, 1950, a left phrenic crush was followed by a pneumoperitoneum, which was kept going for three and a half years. In May, 1954 (Fig. 16), she still showed an occasional positive sputum, and bronchography showed a diseased left

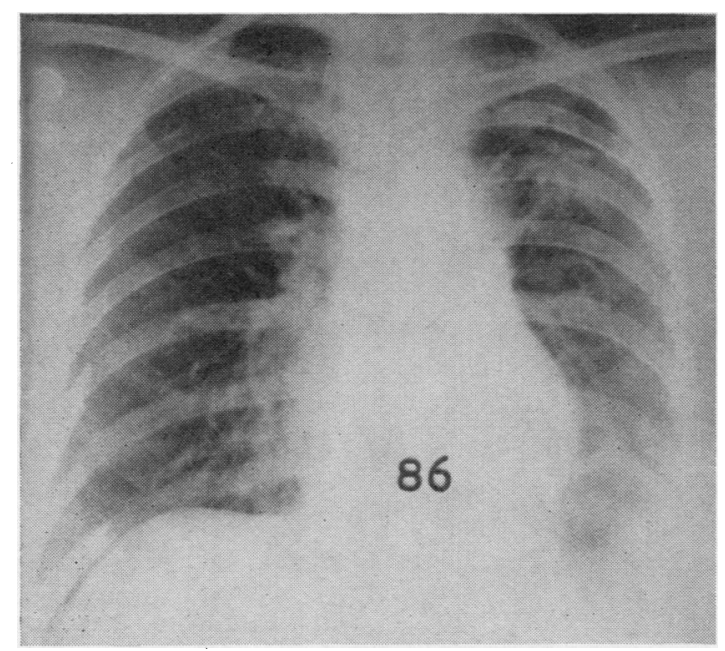

FIG. 16.-Postero-anterior radiograph of Case 86 showing extensive tuberculous disease in the left lung and the elevation of the left diaphragm. The bronchospirometric record of this case is shown in Fig. 17. upper lobe, including the lingula, and the apex of the lower lobe. The M.B.C. was $91 \mathrm{l} . / \mathrm{min}$., and it was thought to be desirable to know what function remained on the left side with the extensive disease and the high diaphragm, in case pneumonectomy should seem desirable at thoracotomy. Broncho-

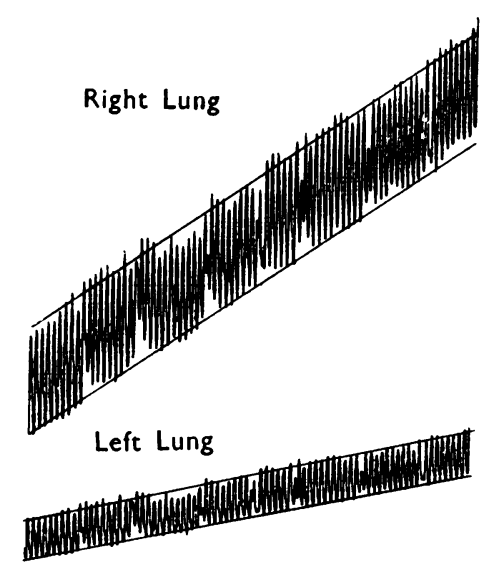

TIME IN MINUTES

\begin{tabular}{lc|c|c}
\hline & & Right Lung & Left Lung \\
\cline { 1 - 3 } $\begin{array}{l}\text { Oxygen uptake } \\
\text { Ventilation }\end{array}$ & $\cdots$ & $\begin{array}{r}210 \mathrm{ml} . / \mathrm{min} .(77 \%) \\
6.01 . / \mathrm{min} .(73 \%)\end{array}$ & $\begin{array}{r}63 \mathrm{ml} . / \mathrm{min} .(23 \%) \\
2.161 . / \mathrm{min} .(27 \%)\end{array}$ \\
\hline
\end{tabular}

Fig. 17.-Tracing of Case 86.

spirometry (Fig. 17) showed that the left lung was performing $23 \%$ of the oxygen uptake and $27 \%$ of the ventilation. It was therefore considered that it would be desirable to preserve any useful lung on that side, but if this was not technically feasible pneumonectomy would be possible.

\section{Discussion}

The results of this investigation stand out clearly. With the Carlens catheter, and with the procedure described and carried out in the type of case studied in this series, bronchospirometry is not a particularly unpleasant procedure for the patient. The patient, in fact, views it with considerably more favour than he accords to other more commonly carried out procedures. Once the equipment has been set up, the tests can be carried out quickly and smoothly by an operator experienced in tracheal intubation. Local anaesthesia need not be elaborate or prolonged; indeed, the initial tracheal injection of amethocaine is probably un- 
necessary and is often dispensed with. It cannot be too much stressed how important are patience and consideration for the patient.

The data obtained in all cases gave a clear indication of the relative functioning capacities of the two lungs, and such information was invariably found to be helpful in deciding the best treatment of the patient. This is particularly of value in cases with already impaired respiratory reserve, where it is often important to know the distribution of this function so that treatment is planned to impair it further as little as possible.

We have found this method of investigation of great importance in assessing the function after pleural effusion or artificial pneumothorax. We believe that it is impossible to make a reliable assessment of function in such cases on clinical or radiological grounds, and the results of bronchospirometry have so repeatedly given us unexpected information that we cease to be surprised.

Cases 5, 20, and 80 illustrate this point. In Case 5 , a lung of almost normal radiological appearances had grossly reduced function, while in Cases 20 and 80 marked clinical and radiological changes were associated with relatively little change in function. Many similar examples could be quoted from the cases in this series, and we feel that bronchospirometry is the only method of study that gives a true indication of function in these patients.

Bronchospirometry is valuable in assessing the impairment of function after major surgery and other procedures, The information gained in the individual case can be of great value in planning further treatment where it proves necessary, and the research value of estimating the functional result after surgery is obvious.

We are impressed with the lack of function in segments which are seen to be bronchiectatic in the bronchogram, even in the absence of symptoms, and feel that the removal of such segments, whether their pathology has a tuberculous basis or not, causes no loss of lung function.

No attempt has been made to cover completely the subject of bronchospirometry. This has already been very adequately done by the series of papers by Gaensler and others (1952-3). The aim of this paper is to present bronchospirometry as a useful and harmless method of investigation which has hitherto been neglected in Great Britain.

\section{SUMMARY}

The literature on the general aspects of the subject of bronchospirometry has been briefly reviewed.

The apparatus and the method used in the studies of this series of patients are described.

The study and follow-up of 125 investigations by bronchospirometry indicate that this is a relatively simple and very useful method of study.

The results are invariably of value in the type of case studied in this series.

The investigation is not unduly unpleasant for the patient, and is associated with no risk.

Grateful thanks are due to the PhysicianSuperintendent, Dr. H. M. Foreman, M.B.E., and to Mr. Dillwyn Thomas and Mr. H. R. S. Harley for their encouragement and co-operation, and to all the many doctors in South Wales who have sent us cases and co-operated in supplying information. Thanks are also due to Mrs. B. Marshall and Mr. Gwilym Jones for their technical assistance and for the photographs, and to Mrs. M. Mear for typing.

\section{REFERENCES}

Baldwin, E. de F., Cournand, A., and Richards, D. W. (1948). Medicine, 27, 243

Bernstein, L., D'Silva, J. L., and Mendel, D. (1952). Thorax, 7, 255. Björkman, S. (1934). Acta med. scand., Suppl. 56.

and Carlens, E. (1951). Ibid., Suppl. 259, p. 63.

Cain, C. C., and Otis, A. B. (1949). J. Aviat. Med., 20, 149.

Carlens, E. (1949). J. thorac. Surg., 18, 742.

Croce, P. (1954). Ibid., 27, 187.

Donald, K. M. (1952). Postgrad. med. J., 28, 171

Gaensler E. A. (1952). J. Lab. clin. Med., 39, 917.

- (1953). Dis. Chest, 24, 390.

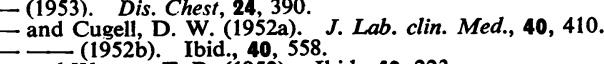

and Watson, T. R. (1952). Ibid., 40, 223.

Maloney, J. V., and Björk, V. O.'(1952). Ibid., 39, 935.

Patton, W. E., and Frank, N. R. (1953). Ibid., 41, 456.

Watson, T. R., and Patton, W. E. (1953). Ibid., 41, 436

Gebauer, P. W. (1939). J. thorac. Surg., 8, 674.

Inada, K. Kishimoto, S., Satô, A., and Watanabe, T. (1954). Ibid.,

27, 173.

Jacobaeus, H. C., Frenckner, P., and Björkman, S. (1932). Acta $\frac{\mathrm{O}}{\mathrm{O}}$ med. scand., $79,174$.

Long, J. H., Norris, C. M., Burnett, W. E., and Wester, M. R. (1950). J. thorac. Surg., 19, 477.

McMichael, J. (1939). Clin. Sci., 4, 167

Marsh, K. (1953). J. thorac. Surg., 25, $495 . \quad$ M. (1948). Ibid., 17, orris,

Prime, F. J., and McMichael, J. (1952). In Diseases of the Chest, ed. Marshall, G., and Perry, K. M. A., vol. 1, p. 39. Butterworth, London.

Wright, G. W., and Mich elson, E. (1950). Meth. med. Res., 2, 82.

Zavod, W. A.'(1940). J. thorac. Surg., 10, 27. 